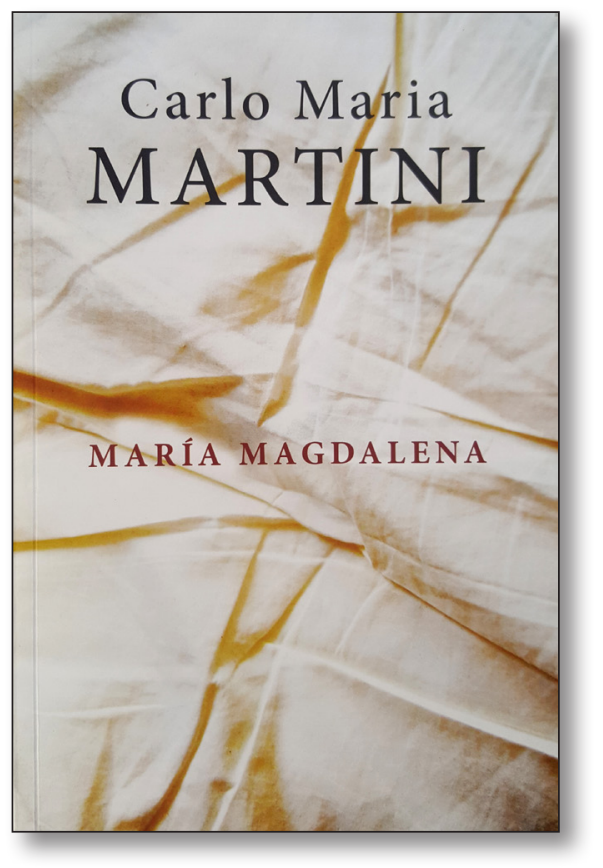

\title{
María Magdalena
}

\author{
Carlo Maria Martini
}

Sal Terrae, 2018.

Carlo Maria Martini (1927-2012), arzobispo de Milán de 1980 a 2002, fue creado cardenal en 1983. Jesuita y biblista de fama internacional, está considerado unánimemente como una de las voces más escuchadas y seguidas, tanto por creyentes como por no creyentes.

Este libro recoge las meditaciones dirigidas por Martini durante una tanda de ejercicios espirituales predicados a las consagradas en el Ordo Virginum de la diócesis de Milán. Estos ejercicios se desarrollaron en los últimos días de diciembre de 2006 y los primeros de enero de 2007, en Quiriat Yearim (Israel).

Han sido innumerables las obras exegéticas, históricas, literarias, hagiográficas, que, a lo largo de la historia, han estudiado a este personaje del Nuevo Testamento. Por otro lado, la figura de la primera persona a quien Jesús encomienda la difusión de la buena nueva se ha puesto de moda, está en el candelero. Pléyade de libros aparecidos actualmente tras el éxito de la novela de Dan Brown El código Da Vinci lo corroboran. Sin embargo, se trata de novelas, leyendas y películas que no contemplan su imagen desde el cristianismo.

La estructura de este libro presenta algunas reflexiones de índole espiritual, poniendo en el centro de estas meditaciones a una mujer extraordinaria, María Magdalena. Los ejercicios espirituales, Encontrar el corazón de Dios, Principio y fundamento, Los siete demonios, El camino de purificación, En busca de Jesús, Solo el exceso salva, El camino de la Cruz, Juzgados en el amor y Las formas del amor constituyen las distintas partes de esta obra.

No le interesa tanto a Martini conocer exactamente la identidad de María Magdalena, aunque lo tratará en su libro para indagar sobre su enfermedad, ni cómo poder distinguirla de las otras, lo cual ha provocado una gran confusión. De esto se ha discutido mucho durante siglos, aunque pocos han hecho referencia a su protagonismo dentro de 
los primeros discípulos de Jesús y menos hablan de la primera aparición y del envío del resucitado.

En este libro de Carlo Maria Martini María Magdalena, destacan tres temas fundamentales: los pecados de María Magdalena, el exceso del bien y el anuncio de la Resurrección.

La primera aportación del libro consiste en tratar de llegar al conocimiento de la grave enfermedad de María Magdalena reflexionando a través de conjeturas.

Martini se pregunta quién es María Magdalena, esa mujer a quien se menciona en los Evangelios tantas veces, incluso más que a María, la madre de Jesús. Y realiza una recensión de sus presencias en ellos.

En Lc 8, 1-3 aparece ya en la vida de Jesús y es donde se habla de ella por primerísima vez, constituyendo una excepción que se recuerde a una mujer de este modo, con algunas otras, en el centro de la vida de Jesús. Lucas acaba de contar el perdón a la mujer pecadora cuyo nombre no sabemos, en casa de Simón el fariseo, y después dice: «Lo acompañaban los Doce y algunas mujeres que había sanado de espíritus inmundos y de enfermedades: María, llamada Magdalena, de la que habían salido siete demonios; Juana, mujer de Cusa, mayordomo de Herodes; Susana y otras muchas, que los servían con sus bienes».

Lucas describe a María de Magdala en primer lugar y de una manera bastante sorprendente, porque de ella habían salido siete demonios. Se trata de la única persona de la que se dice esto. Y Martini intenta comprender qué puedan ser estos siete demonios. Señala el autor que las otras mujeres estaban un poco enfermas, todas tenían alguna dificultad y ella tenía ciertamente alguna dificultad más grande que las otras, algo gravemente nocivo.

Para intentar comprender de qué tipo era esta grave enfermedad, Martini afirma que hay cuatro vías que se pueden seguir:

- La primera sería la vía de la desviación sexual. Para algunos era una prostituta, ya que en el pasaje inmediatamente anterior Lc 7, 36 se describe el perdón de una prostituta en casa de Simón el fariseo, al que sigue Lc 8, 1-3 donde se menciona a María Magdalena. Sin embargo, Martini considera más probable la opinión de los que dicen que se trata de dos personas distintas, descartando la desviación sexual.

- Una segunda vía es la de una desviación psicológica y de salud general. Se trataría de una persona deprimida, quizás anoréxica o esquizofrénica, típico de la presencia demoníaca, de los espíritus impuros, y quizás se trataría de algo recurrente. Para comprobarlo, Martini recuerda el pasaje de Mt 12,43, donde viene a decir Jesús que cuando un demonio es expulsado de un hombre, coge a siete peores que él y vuelve y le atormentan con mayor furor. Por tanto, esta idea de «siete» indicaría una dimensión de recurrencia. Parecía estar mejor, después habría recaído en su estado de depresión, de anorexia u otras enfermedades graves.

- En una posible tercera vía, más espiritual, María Magdalena habría vivido una situación opresiva de pecado, de la que no se podría salir, como le ocurría también a Zaqueo, episodio narrado por Lc 19, 2, prisionero de su situación de pecado pero a quien Jesús trae la salvación. Sin embargo, María Magdalena era prisionera de un modo más grave. Y Martini piensa que pueda buscarse su maldad en los vicios que Gal 5, 16-22 señala, pecados "carnales" y otros como idolatría, hechicería, iras, embriagueces, orgías, contrarios a la vida según el espíritu.

- También piensa Martini, y se trataría de una cuarta vía, en una enfermedad grave de María Magdalena, acompañada de depresión, amargura, falta de autodominio, desorden interior. 
Sin embargo, los Evangelios no señalan ninguna de ellas con certeza, según el autor, pero seguro que se encontraba atrapada en una situación casi incurable, crónica, recurrente, y había salido completamente de ella. Siete demonios constituyen un número completo e indicarían una serie de situaciones incurables, que nos haría comprender el amor y la entrega de María Magdalena hacia Jesús tras su liberación. Por tanto, lo importante no sería tanto saber cuáles fueron estos siete demonios, sino el haber sido liberada de ellos y conocer su reacción de agradecimiento y alegría por su nueva situación de curada de ese mal. Lo importante es que el encuentro con Jesús, que no sabemos si fue uno solo o se repitió, cambió su vida, siendo su fe en Él más preciosa que el oro.

La segunda aportación de Martini en esta obra sobre la figura de María Magdalena consiste en considerarla el signo del exceso cristiano. Ella representa el signo del ir más allá del límite, es el signo de la superación; del mismo modo que su maestro, que fue más allá de lo debido, como entrega gratuita y total al hombre. En esto, dice el autor, consiste el secreto de la vida. Quien pretenda vivir solo según el equilibrio perfecto del do ut des no llega a captar el sentido de la existencia, que es, más bien, dar más allá de lo debido. Y así nos lo han mostrado Jesús y María Magdalena, como su discípula, en la Escritura.

Solo el exceso salva, dice Martini. Se trata de dar a fondo perdido, de dar gratuitamente, de algo excedente, de un desequilibrio de la existencia, algo que se sale de las vías ordinarias de la vida cotidiana. Se trata de un exceso del bien, trabajar a fondo perdido, cuando se sale de las convenciones sociales.

Y así, cuando en el evangelio de Lucas [7, 36-50] entra la mujer pecadora, para algunos María Magdalena, en casa de Simón, el fariseo, y sin que nadie la espere, se lanza a la sala del banquete, bañando los pies de Jesús con sus lágrimas y enjugándolos con sus cabellos, haciendo decir a Simón: "Si supiera quién es esta mujer, no admitiría todo esto", nos encontramos, dice Martini, ante un exceso del bien. Pero también tiene lugar un exceso del bien cuando rompe el frasco de alabastro y derrama sobre su cabeza el ungüento anticipándose a embalsamar su cuerpo para la sepultura, como dice Marcos [14, 3-9]. Bastaba con verterlo de manera que se pudiera conservar el alabastro, en vez de romperlo: es un exceso del bien. ¿Para qué se ha hecho este derroche de perfume?, decían indignados algunos de los presentes en casa de Simón,el leproso; se podía haber vendido este perfume por más de trescientos denarios, y darlo a los pobres. Esta mujer trató a Jesús con un exceso de delicadeza, al derramar sobre Él un frasco de alabastro con perfume de nardo puro de mucho precio, dice el evangelista Marcos. El precio de trescientos denarios era aproximadamente el sueldo de un obrero durante todo un año, constituyendo una acción muy generosa. Este gesto de María Magdalena, derramar hasta la última gota del perfume, indica su entrega total a Jesús, Él lo merece todo.

Son muchos los actos de exceso en el bien que se contraponen a los que se hacen para el mal. Lo que une a Dios y lo que ata a la tierra. Fue un exceso del bien el beso de san Francisco al leproso, o la fundación de la congregación para los moribundos de santa Teresa de Calcuta, o las salidas de don Quijote de su aldea en defensa de los ideales de justicia y equidad.

Finalmente, nos encontramos con una tercera novedad en el libro de Martini. A María Magdalena no se le da el encargo de anunciar al mundo la Resurrección, sino de referirla a la Iglesia, es decir, anunciar a los Apóstoles que Jesús, habiendo resucitado, se le apareció a ella. Así nos lo cuenta el evangelista Marcos en el capítulo 16, 1-11. Esto constituye un signo de gran confianza, un encargo que la rehabilita, que la pone en la plenitud de su dignidad y de sus capacidades. A María se le ha confiado el anuncio de la Resurrección, no es solo para ella, y ella comunica a los Apóstoles la profunda experiencia que ha tenido, con lo 
que se nos da a entender que el anuncio de la Resurrección pasa por la Iglesia. Y este anuncio llega hasta nosotros a través del testimonio de los Apóstoles y de la Iglesia primitiva. Esto no quiere decir que ella no pueda anunciar después, públicamente, el Evangelio y proclamarlo. Jesús aprecia su entrega, su amor, su coraje, su lealtad y la constituye en la primera depositaria del misterio de su resurrección dándole una misión eclesial.

En definitiva, el libro de Martini nos muestra la historia de María Magdalena como un símbolo del exceso, del derroche, de la superación, de la entrega, del coraje, de la lealtad y del amor. Más allá de lo cotidiano el hombre alcanza su verdadera realización, su dignidad. Solo el exceso salva. 